TITLE:

\title{
An approach of optimal design of HTS synchronous motor using genetic algorithm
}

$\operatorname{AUTHOR}(S)$ :

Han, SI; Muta, I; Hoshino, T; Nakamura, T

\section{CITATION:}

Han, SI ... [et al]. An approach of optimal design of HTS synchronous motor using genetic algorithm. IEEE TRANSACTIONS ON APPLIED SUPERCONDUCTIVITY 2004, 14(2): 896-899

\section{ISSUE DATE:}

2004-06

URL:

http://hdl.handle.net/2433/39954

\section{RIGHT:}

(c)2004 IEEE. Personal use of this material is permitted. However, permission to reprint/republish this material for advertising or promotional purposes or for creating new collective works for resale or redistribution to servers or lists, or to reuse any copyrighted component of this work in other works must be obtained from the IEEE. 


\title{
An Approach of Optimal Design of HTS Synchronous Motor Using Genetic Algorithm
}

\author{
Sang-Il Han, Itsuya Muta, Tsutomu Hoshino, and Taketsune Nakamura
}

\begin{abstract}
This paper describes an optimal design of $100 \mathrm{HP}, 4$ pole, $1800 \mathrm{rpm}$ High Temperature Superconducting (HTS) synchronous motor in terms of energy efficiency and downsizing, i.e., specific power density. Bi-2223/Ag multifilamentary tape is used as a material of HTS field coil. Design variables and constraints are appropriately set up in consideration of electromagnetic characteristics. Size of the rotor and the stator is calculated with fundamental expressions based on the two-dimensional electromagnetic analysis. As an optimization technique to obtain the dimension of optimal specific power density or energy efficiency of the HTS motor, genetic algorithm (GA) which is well-known as aglobal optimal technique modeled on the concept of natural selection and evolution has been used. Electrical characteristics such as efficiency and V-curve for the HTS motor optimally designed are also investigated.
\end{abstract}

Index Terms-Bi-2223/Ag HTS tape, energy efficiency, HTS synchronous motor, optimal design, specific power density.

\section{INTRODUCTION}

$\mathbf{I}$ N RECENT TIMES, the HTS synchronous motors have attracted the attention because of their economical advantage as well as high efficiency, small size, and light weight compared to the conventional motors.

Significant advances in the development of HTS wire have made it possible that the commercialization of the HTS motors at power ratings much lower than can be considered in Low Temperature Superconducting (LTS) motors are economically feasible. These potential benefits are expected to introduce them into marine transportation systems such as naval and commercial ship propulsion, where size and weight are important for design flexibility, as well as industrial systems such as steel milling, pulp processing and chemical gas refining [1]-[3].

In this paper, as a part of the 21 st Century Frontier R\&D Program of Korea, an optimal design of HTS synchronous motor of 3-phase, 4-pole, $100 \mathrm{HP}$ capacity is dealt with based on the fundamental expressions of electromagnetic field [4]-[6]. For the optimal design of HTS synchronous motor, the GA that is a global optimization technique based on evolutionary computing techniques is utilized.

The HTS motor is designed in order to optimize energy efficiency and specific power density, and actually loss and volume are evaluated as specified objectives. Several design variables

Manuscript received October 21, 2003. This work was supported in part by the 21 st Century Frontier R\&D Program of Korea Ministry of Science and Technology in Korea, and The 21st Century COE Program 14213201 in Japan.

The authors are with the Electrical Engineering Department, Kyoto University, Kyoto, 615-8510, Japan (e-mail: sihan@asl.kuee.kyoto-u.ac.jp; muta@kuee.kyoto-u.ac.jp; hosinio@asl.kuee.kyoto-u.ac.jp; tk_naka@kuee. kyoto-u.ac.jp).

Digital Object Identifier 10.1109/TASC.2004.830312

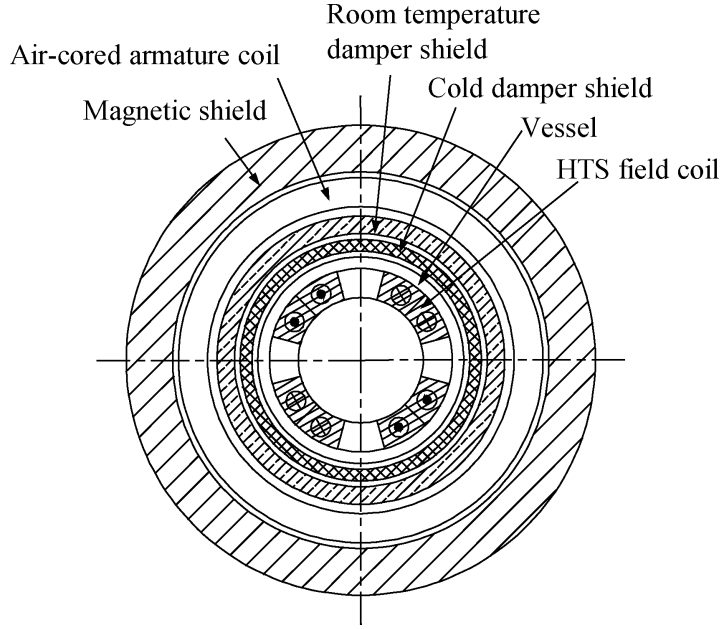

Fig. 1. Schematic cross section view of HTS motor.

and constraints are appropriately given in consideration of electromagnetic characteristics of the HTS motor as well as material properties and manufactural restriction of each component. Electrical characteristics of the HTS motor using design specifications and results are investigated. In consequence, the design method used in this paper would clarify to be effective and reasonable to optimize energy efficiency and specific power density of the HTS motor, and aid the optimal design process of the HTS motor.

\section{BASIC STRUCTURE OF HTS MOTOR}

\section{A. Rotor Structure}

Fig. 1 shows schematic cross section of the HTS motor. The rotor includes HTS field coil, supporting cylinder, vessel, cold damper shield and room temperature damper shield. The stator consists of air-cored armature coil and magnetic shield.

The HTS field coil is composed of double pancake coil wound with Bi-2223/Ag multifilamentary tape, and it also consists of racetrack type. In the design of the HTS field coil operated at about $30 \mathrm{~K}$, the operating current of the HTS field coils is determined on the basis of the load characteristic given by design specifications of the HTS field coil and $I_{c}-B$ characteristic of a short sample of HTS tape conductor [5], [7]. The HTS tape has anisotropic characteristics, i.e., more sensitive to magnetic field applied perpendicular to the tape surface $\left(B_{\perp}\right)$ than to the magnetic field parallel to the tape surface $\left(B_{/ /}\right)$.

Therefore, in this paper, only load characteristic of magnetic field perpendicular to the tape surface is considered to assure higher stability in design of the HTS field coil. Fig. 2 shows 


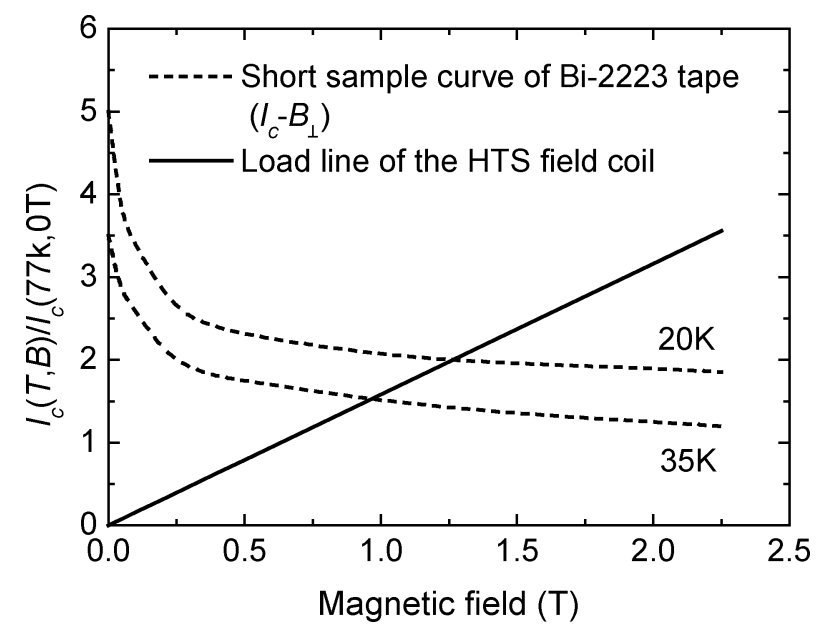

Fig. 2. Relative critical current in magnetic field applied perpendicular to the tape surface.

variation of relative critical current to magnetic field applied perpendicular to the tape surface [8].

Both the cold damper shield and the room temperature damper shield are composed of outer conductive layer and inner support layer, respectively. The cold damper shield serves to reduce radiation heat from the outside and low-frequency asynchronous magnetic field caused by the armature coil. The room temperature damper shield serves to decrease mechanical rotor fluctuation and high-frequency asynchronous magnetic field. The vacuum spaces between the vessel and the cold damper shield, and between the cold damper shield and the room temperature damper shield are installed as the measure to shield heat conduction.

\section{B. Stator Structure}

The armature coil is inserted into slots of nonmagnetic Glass Fiber Reinforced Plastic (GFRP), which supports the armature coil against large electromagnetic force and is used instead of iron core because iron core is subject to saturation by large magnetic flux generated from the HTS field coil. The armature coil is composed of transposed strand conductors and some cooling channels to reduce resistive and eddy current losses. The magnetic shield placed in the most exterior of the stator prevents magnetic field from being leaked to the outside. The magnetic shield also increases inner magnetic flux and shapes sinusoidal magnetic flux distribution. In design of the magnetic shield, its thickness should be determined not to be saturated by tangential flux density.

\section{OPTIMAL DESIGN}

\section{A. Optimization Technique}

To optimize energy efficiency and specific power density of the HTS motor, the GA is utilized as an optimization technique. The GA is a well-known global optimization method based on the natural evolutionary theory such as selection and survival of the fittest. Many works using the GA have proved that it is well suited for various optimization problems and it provides relatively fast convergence less subject to be trapped in local optima [9]-[13]. The optimization procedure is follows: first,
TABLE I

DESIGN SPECIFICATION OF HTS MOTOR

\begin{tabular}{|c|c|}
\hline Item & Value \\
\hline Output power $P_{o}$ & $100 \mathrm{HP}$ \\
\hline Voltage $V_{t}$ & $380 \mathrm{~V}$ \\
\hline Number of pole $p$ & 4 \\
\hline Power factor & 1.0 P.F. \\
\hline Frequency $f$ & $60 \mathrm{~Hz}$ \\
\hline Synchronous speed $N_{S}$ & $1800 \mathrm{rpm}$ \\
\hline Synchronous reactance $x_{d}$ & 0.2 p.u \\
\hline Current of HTS field coil $I_{f}$ & $100 \mathrm{~A}$ \\
\hline
\end{tabular}

a initial population that consists of a set of design variables is randomly made, and using genetic operator such as selection, crossover, mutation and reproduction, a new one is remade, and then the objective function is evaluated. This procedure is continued until the termination criterion (i.e., generation number, which is here set up as 20000) is satisfied [9]. Here, the real coding representation to represent design variables is utilized for the design of HTS motor. The crossover is applied by the direction-based crossover that uses the values of objective function in determining the direction of genetic search. The nonuniform mutation is introduced as the method of mutation and it is designed for fine-tuning capabilities aimed at achieving high precision [9], [11], [12]. The possibility of crossover and mutation is fixed as 0.5 and 0.1 , respectively.

\section{B. Application to Design of HTS Motor}

In the optimization problem of energy efficiency and specific power density of the HTS motor, as the first step, its loss and volume are actually minimized as objective function, respectively, subject to some constraints using the GA [11], [12]. At the second step, in order to find an appropriate design value between the two objective functions, a multiobjective optimization technique of weighted min-max approach as well as the GA is utilized [11], [12]. Specifications for the optimal design of the HTS motor are shown in Table I.

Design variables are defined as follows: Mean radius of the HTS field coil $r_{f}$, thickness of the HTS field coil $t_{f}$, inner radius of the magnetic shield $r_{m}$, thickness of the air-gap armature coil $t_{a}$ and air-gap length between the rotor and the stator $t_{R S}$. The size of components related to mechanical characteristics such as vessel, damper supports and vacuum layers is fixed as appropriate values to have enough strength.

Constraints are given considering manufactural restrictions and material properties on the basis of electrical characteristics, that is, two values of inner radius of the stator $r_{a i}$ and magnetic field density of the HTS field coil $B_{m}$, respectively, obtained from the fundamental expression equations are set up to satisfy an allowable deviation value. Besides, equivalent end length of the armature coil $l_{e}$ and magnetic flux density of the armature coil $B_{a}$ are settled to satisfy required value, respectively [11], [12]. For the purpose of high energy efficiency and downsizing, loss and volume of the HTS motor are minimized as objective functions, respectively. Except loss of refrigerator, total loss of the HTS motor mainly consists of copper loss of the armature coil, iron loss of the magnetic shield, mechanical loss, stray load 
TABLE II

DESIGN RESULTS OF HTS MOTOR

\begin{tabular}{|c|c|c|c|c|}
\hline Item & $\mathrm{S}$ & $\mathrm{A}$ & $\mathrm{B}$ & $\mathrm{C}$ \\
\hline \multicolumn{5}{|l|}{ Design variable } \\
\hline $\begin{array}{l}\text { Mean radius of HTS field coil } r_{f} \\
(\mathrm{~mm})\end{array}$ & 126 & 177.5 & 119.9 & 148. \\
\hline $\begin{array}{l}\text { Thickness of HTS field coil } t_{f} \\
(\mathrm{~mm})\end{array}$ & 28 & 23.8 & 27.7 & 25 \\
\hline $\begin{array}{l}\text { Inner radius of magnetic shield } \\
r_{m}(\mathrm{~mm})\end{array}$ & 210 & 253.0 & 204.1 & 228 \\
\hline $\begin{array}{l}\text { Thickness of air-gap armature } \\
\text { coil } t_{a}(\mathrm{~mm})\end{array}$ & 20 & 26.2 & 28.4 & 27 \\
\hline $\begin{array}{l}\text { Air-gap length between rotor } \\
\text { and stator } t_{R S}(\mathrm{~mm})\end{array}$ & - & 2.0 & 2.0 & 2 \\
\hline \multicolumn{5}{|l|}{ Objective function } \\
\hline Volume $V\left(\mathrm{~m}^{3}\right)$ & 0.083 & 0.07 & 0.088 & 0.074 \\
\hline Loss $P$ & 5.72 & 5.399 & 4.578 & 4.796 \\
\hline$(\mathrm{kW})$ & 2.485 & 1.366 & 1.461 & 1.391 \\
\hline Iron lo & 0.32 & 1.222 & 1.15 & 1.148 \\
\hline Mechan & 1.497 & 1.843 & 1.276 & 1.443 \\
\hline y loc & 0.994 & 0.41 & 0.438 & 0.417 \\
\hline Eddy current loss $P_{e}(\mathrm{~kW})$ & 0.423 & 0.558 & 0.253 & 0.397 \\
\hline $\begin{array}{l}\text { Open-circuit transient time } \\
\text { constant } T_{d o}(\mathrm{sec})\end{array}$ & 100 & 100 & 100 & 100 \\
\hline $\begin{array}{l}\text { Open-circuit subtransient time } \\
\text { constant } T_{d o}{ }^{\prime \prime}(\mathrm{sec})\end{array}$ & 1.5 & 0.5 & 0.5 & 0. \\
\hline $\begin{array}{l}\text { Open-circuit sub-subtransient } \\
\text { time constant } T_{d o}{ }^{\prime \prime}(\mathrm{sec})\end{array}$ & - & 0.02 & 0.02 & 0 . \\
\hline Transier & 0.17 & 0.142 & 0.149 & 0.144 \\
\hline$d^{\prime \prime}($ p.u. $)$ & 0.11 & 0.117 & 0.105 & 0.110 \\
\hline Sub-subtransient reactance $x_{d}^{\prime \prime \prime}($ p.u. $)$ & 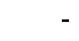 & 0.102 & 0.075 & 0.089 \\
\hline Magnetic flux of HTS field coil $B_{f}(\mathrm{~T})$ & 0.6 & 0.55 & 0.55 & 0.55 \\
\hline Magnetic flux of armature coil $B_{a}(\mathrm{~T})$ & 0.31 & 0.30 & 0.21 & 0.26 \\
\hline $\begin{array}{l}\text { Turns number of armature coil per } \\
\text { phase } N_{a} \text { (turn) }\end{array}$ & 64 & 34 & 28 & 3 \\
\hline $\begin{array}{l}\text { Turns number of HTS field coil } \\
\text { per pole } N_{f} \text { (turn) }\end{array}$ & 1230 & 539 & 424 & 484 \\
\hline Outer diameter of rotor $D_{R}(\mathrm{~mm})$ & - & 440.4 & 338.0 & 387.4 \\
\hline netic shield $l_{m}(\mathrm{~mm})$ & 462 & 242.9 & 525.1 & 333.0 \\
\hline Energy efficiency $\eta(\%)$ & 92.9 & 93.3 & 94.2 & 93.9 \\
\hline Specific power density $S P D\left(\mathrm{~kW} / \mathrm{m}^{3}\right)$ & 0.9 & 1.08 & 0.85 & 1.0 \\
\hline
\end{tabular}

$\mathrm{S}$ : Conceptional design (- : Unknown data) [5].

A: Specific power density (volume) optimization.

B: Energy efficiency (loss) optimization.

C: Optimization of specific power density and energy efficiency.

loss and eddy current loss of the armature coil [11], [12]. The other objective function, volume can be simply represented with outer diameter of the magnetic shield $D_{m o}$ and length of the magnetic shield $l_{m}$ [11], [12].

\section{RESULTS AND DisCUSSIONS}

\section{A. Design Results}

Design results obtained by minimizing loss and volume of the HTS motor for optimization of energy efficiency and specific power density using the GA are shown in Table II, compared to those of conceptional design [5]. As shown in Table II, the radial size of the rotor in design results for volume (i.e., specific power density) optimization (A case) is larger than that of loss (i.e., energy efficiency) optimization (B case). On the other hand, the axial length of the rotor in the former is shorter than that in the latter. In order words, two objective functions come into conflict with each other dimensionally.

Therefore, to find the compromise design value, multiobjective optimization is carried out using weighed min-max

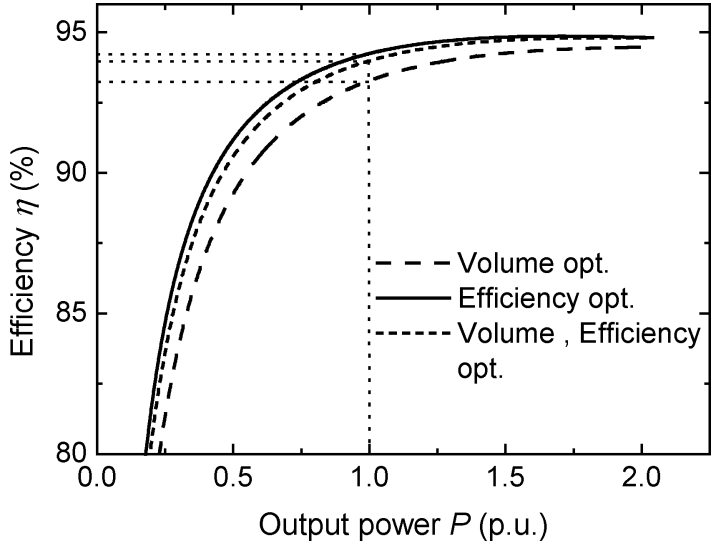

Fig. 3. Variation of efficiency versus output power at rated load $(1.0$ p.u. $=$ $100 \mathrm{HP}$ ).

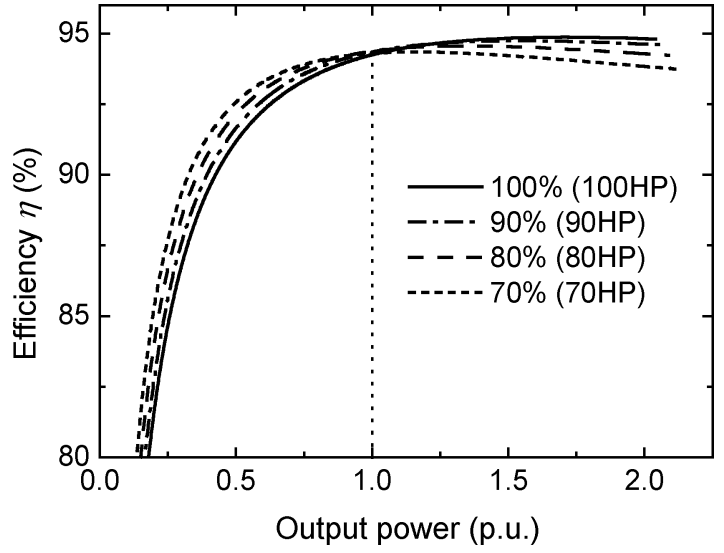

Fig. 4. Variation of efficiency versus output power at partial load $(1.0$ p.u. $=$ $100 \mathrm{HP})$.

approach, in which ideal solutions of loss and volume are given as the optimums of loss and volume and weighted coefficients are given for loss and volume to have equal importance, i.e., 0.5 and 0.5 , respectively. The compromise design values (C case) are shown in Table II.

\section{B. Characteristics of HTS Motor}

Using electrical parameters given from design results of the HTS motor as well as design specifications, its characteristics are investigated as follows:

1) Characteristics of Efficiency: For the HTS motor with dimensions obtained by volume optimization, loss optimization and optimization of volume and loss (A, B, and C cases), variation of efficiency to output power is shown in Fig. 3, respectively. Maximum efficiency for all cases is at overload point of output power as shown in Fig. 3.

Based on the dimensions and parameters obtained by optimal efficiency design of the HTS motor at some partial loads of output power (70, 80 and 90\%), relationship between efficiency and output power is shown in Fig. 4. Efficiency of the HTS motor designed at partial loads is a little higher than those at full load until rated output power.

2) Characteristics of V-Curve: V-curve means relationship between field current and armature current. For output 


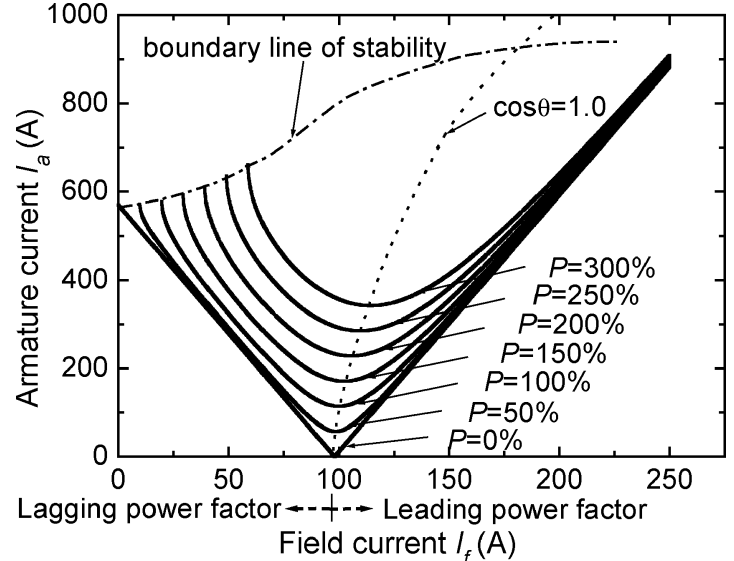

Fig. 5. Variation of armature current versus field current at some load $(1.0$ p.u. $=100 \mathrm{HP})$.

power from no-load to $300 \%$, variation of armature current versus field current is shown in Fig. 5. Generally, saturation of the stator core occurs in conventional motor. However, because the stator core of the HTS motor is made of nonmagnetic materials, the saturation effect does not appear and armature current against field current increases linearly.

\section{CONCLUSIONS}

In this paper, the optimal design of the HTS motor based on theoretical electromagnetic analysis has been carried out. Specific power density and energy efficiency of the HTS motor have been optimized using the GA, respectively, subject to several constraints. The optimal design of energy efficiency has resulted in smaller radius and longer axis length in the dimension than those of specific power density. Also, the multiobjective optimal design taking into account both energy efficiency and specific power density has come to the compromise design values. It has been implemented by using weighted min-max approach. To evaluate electrical characteristics of the HTS motor designed optimally, the characteristics such as efficiency and V-curve have been investigated.
As a result, through the results obtained by optimal design method used in this paper and investigations of electrical characteristics, it would be clarified that such a design method is useful and suitable for optimal design of the HTS motor.

\section{REFERENCES}

[1] W. Nick, G. Nerowski, H. W. Neumuller, M. Frank, P. Hasselt, J. Frauenhofer, and F. Steinmeyer, "380 kW synchronous machine with HTS rotor windings-development at siemens and first test results," Physica C, vol. 372, no. 375, pp. 1506-1512, 2002.

[2] K. Swarn, "Development status of superconducting rotating machines," presented at the IEEE PES Meeting, New York, Jan. 27-31, 2002, IEEE CD Cat\#02CH37309C.

[3] M. Frank, J. Frauenhofer, P. Hasselt, W. Nick, H. W. Neumuller, and G. Nerowski, "Long-term operational experience with first siemens 400 kW HTS machine in diverse configurations," IEEE Trans. Appl. Supercond., vol. 13, no. 2, pp. 2120-2123, Jun. 2003.

[4] I. Muta, T. Hoshino, and K. Hayahsi, "Fundamental design and electrical characteristics of superconducting commutatorless motor," IEE Trans. of Japan, vol. 114-D, no. 2, pp. 197-206, Feb. 1994.

[5] H. M. Jang, I. Muta, T. Hoshino, T. Nakamura, S. W. Kim, M. H. Sohn, Y. K. Kwon, and K. S. Ryu, "Design and electrical characteristics analysis of 100 HP HTS synchronous motor in 21st century frontier project, Korea," IEEE Trans. Appl. Supercond., vol. 13, no. 2, pp. 2197-2200, Jun. 2003.

[6] N. Maki, "Study on the Practical Design and Trial Manufacture of Superconducting Generator," Ph.D. dissertation, Dept. Elect. Eng., Kyoto Univ., Kyoto, Japan, 1994.

[7] S. K. Baik, M. H. Sohn, S. W. Kim, E. Y. Lee, and Y. K. Kwon, "A 100 HP HTS motor design and the performance analysis," Journal of the Korea Institute of Applied Superconductivity and Cryogenics, vol. 4, no. 2, pp. 31-37, 2002.

[8]. Data of material property of Bi-2223 HTS tape produced by American Superconductor Available. [Online] http://www.amsuper.com/ $\mathrm{html} /$ products/htsWire/

[9] M. Gen and R. Cheng, Genetic Algorithms and Engineering Design: A Wiley Interscience Publication, 1997, pp. 42-67.

[10] R. Saleh and H. Bolton, "Genetic algorithm-aided design of a fussy logic stabilizer for a superconducting generator," IEEE Trans. Power Systems, vol. 15, no. 11, pp. 1329-1335, Nov. 2000.

[11] S. I. Han, I. Muta, H. Hoshino, and T. Nakamura, "Multiobjective optimal design of superconducting generator using genetic algorithm," in Proc. 4th Asia-Pacific Conference on Simulated Evolution and Learning, Singapore, 2002, pp. 60-64.

[12] - "200 MW class superconducting generator design by use of GA," in Proc. Inter. Conf. Electrical Engineering, Hong Kong, 2003, paper no. 119.

[13] D. J. Sim, H. K. Jung, S. Y. Hahn, and J. S. Won, "Application of vector optimization employing modified genetic algorithm to permanent magnet motor design," IEEE Trans. Magnetics, vol. 33, no. 3, pp. 1888-1891, Mar. 1997. 